\title{
Hydraulic Properties and Microgeometry Evolution Accompanying Limestone Dissolution by Acidic Water
}

\author{
C. Noiriel ${ }^{1,2}$, D. Bernard ${ }^{3}$, Ph. Gouze ${ }^{1}$ and X. Thibault ${ }^{4}$ \\ 1 Laboratoire de Tectonophysique, Institut des Sciences de la Terre, de l'Environnement et de l'Espace, \\ CNRS, université de Montpellier II, cc MSE, 34095 Montpellier Cedex 5 - France \\ 2 École des Mines de Paris, Centre d'Informatique Géologique, UMR Sisyphe 7619, 77305 Fontainebleau Cedex 5 - France \\ 3 Institut de Chimie de la Matière Condensée de Bordeaux, CNRS, 33608 Pessac Cedex - France \\ 4 European Synchrotron Radiation Facilities, ID19, BP 220, 38043 Grenoble Cedex 9 - France \\ catherine.noiriel@enspm.fr - philippe.gouze@msem.univ-montp2.fr - bernard@icmcb.u-bordeaux1.fr - thibaul+@esrf.fr
}

\begin{abstract}
Résumé - Évolution des paramètres hydrauliques et de la microgéométrie d'un calcaire pendant sa dissolution par une eau acide - Nous reportons dans cet article les résultats d'une expérience de percolation réactive menée, à température ambiante, dans un calcaire poreux par une eau saturée en $\mathrm{CO}_{2}$ à la pression partielle de $0,1 \mathrm{MPa}$, afin d'évaluer les relations entre la chimie de l'eau et les modifications hydrodynamiques et structurales de l'échantillon. Une méthode d'analyse, basée sur l'utilisation répétée de l'imagerie microtomographique à rayons $\mathrm{X}$, a été développée pour suivre en détail l'évolution de la structure et de l'interface fluide-solide de l'échantillon, tandis que sa porosité et sa perméabilité augmentaient au cours de sa dissolution. Plusieurs mécanismes à l'origine de l'augmentation rapide de la perméabilité ont été identifiés. Au début de l'expérience, cette augmentation a été reliée à la dissolution et à la migration concomitantes de particules carbonatées. Ensuite, la perméabilité a continué d'augmenter par suite de la dissolution des aspérités à l'interface fluide-solide, et de l'accroissement de la connectivité du réseau poral.
\end{abstract}

\footnotetext{
Abstract - Hydraulic Properties and Microgeometry Evolution Accompanying Limestone Dissolution By Acidic Water - A reactive flow-through experiment by carbon dioxide-saturated water at the partial pressure of $0.1 \mathrm{MPa}$ and room temperature was conducted on a porous limestone in order to identify the relationships between fluid chemistry, hydrodynamics and structural properties. Periodic imaging by non destructive X-ray microtomography allowed following the evolution of the core micro-geometry and fluid-rock interface in detail while its porosity and permeability increased due to dissolution. Several mechanisms were successively involved in the rapid permeability increase. Early in the experiment, the permeability increase was related to concomitant particle dissolution and displacement. Later on, permeability continued to rise due to solid-fluid interface smoothing and to pore connectivity increase.
} 


\section{INTRODUCTION}

Pore network structure, porosity and permeability of reservoir rocks can be strongly altered when they are subject to natural or anthropogenic hydrogeochemical forcing. In natural environment, reactive fluids induce pore microgeometry and flow properties complex alteration patterns due to the high level of mineralogical and structural heterogeneity. Experimental constraints are necessary to identify the controlling processes and to work out predictive models.

Recent advances in X-ray computed microtomography $(\mathrm{C} \mu \mathrm{T})$ have considerably improved the direct measurement of multi-granular porous media structure (Coker et al., 1996; Lindquist et al., 1996; Delerue et al., 1999; Lindquist and Venkatarangen, 2000; Proussevitch and Sahagian, 2001). $\mathrm{C} \mu \mathrm{T}$ is a $3 \mathrm{D}$ nondestructive radiographic imaging technique with a spatial resolution limited by the width of the beam, the scintillator efficiency, the number of pixels on the camera and the X-ray absorption coefficient of the rock-forming minerals. Currently, the technique allows the acquisition of $2048^{2}$ pixels radiographies of rock with a pixel size up to $0.3 \mu \mathrm{m}$ using a synchrotron as X-ray source. In earth science, $\mathrm{C} \mu \mathrm{T}$ is often used to determine $3 \mathrm{D}$ pore structure in order to constrain flow models for example (e.g. Spanne et al., 1994; Cole et al., 1996; Auzerais et al., 1996; Nakashima and Watanabe, 2002). Moreover, $\mathrm{C} \mu \mathrm{T}$ is a perfect tool to perform dynamic experiments because the acquisition time is sufficiently short (about $2 \mathrm{~h}$ ). Accordingly, structural changes due to thermal, mechanical or hydrochemical processes can be investigated by alternating experimental episodes and imaging stages. A few experiments using $\mathrm{C} \mu \mathrm{T}$ have recently been published, for example, in relation with the sintering or compaction of glass beads (Bernard et al., 2002; Bernard et al., 2004; Richard et al., 2003), the crack growth in mortar under compressive loading (Landis et al., 2003), or the dissolution of fractures in carbonated rocks (Gouze et al., 2003). Presently, most of the technological and data processing problems have been resolved and complex media can be investigated.

The aim of this work is to document the relationships between the alteration of a natural biogenic porous limestone and the permeability changes due the reactive percolation of $\mathrm{CO}_{2}$-enriched water. In the petroleum industry, massive $\mathrm{CO}_{2}$ injection is routinely used to enhance oil recovery. It has been proposed to apply this method to underground carbon sequestration for mitigating its level increase in the atmosphere (Lackner, 2003). Rationally, depleted oil reservoirs are potential geologic host formations. In these environments, carbonates are present either as the main minerals or as the cement fraction in sandstones. Their thermodynamic equilibrium depends strongly on the $\mathrm{CO}_{2}$ activity in the fluid. Furthermore, the dissolution and precipitation kinetics of those species are fast compared to that of silicate and alumino-silicate species, so that they are the first minerals that are altered by acidic fluids. In the course of supercritical $\mathrm{CO}_{2}$ injection in depleted reservoirs, the interactions of carbon dioxide with formation water and minerals involve high temperature (e.g. 50 to $150^{\circ} \mathrm{C}$ ), high pressure (e.g. $5 \mathrm{MPa}$ to $60 \mathrm{MPa}$ ) and frequently high salinity (up to several molar). Theoretically, these reservoir conditions can be reproduced in the laboratory. Nevertheless, some physico-chemical parameters are still unknown, such as kinetic laws for mineral reactions. Reliable comparisons between experiment and model could not be made as long as these parameters will be unspecified. Moreover, some unknowns still exist at low temperature and pressure. Specifically, carbonate mass transfers and their feedback on hydrodynamic property (i.e. porosity, permeability, dispersivity) changes are difficult to model in polycrystalline heterogeneous rocks. In particular, experimental data are insufficient to tackle the phenomenological relationships between hydrodynamic properties, pore network and reactive surfaces. The understanding of these relationships requires, in a first approach, to do experiment on materials with well-defined geometry and simple mineralogy, for which solubility, kinetics and mechanisms of reaction are well-known. The ideal system with which to start is certainly calcite dissolution at low temperature and $P_{\mathrm{CO}_{2}}$ less than 0.11 MPa, (e.g. Plummer et al., 1978; Plummer and Busemberg, 1982; Chou et al., 1989).

At field scale, direct measurements of the permeability in the course of injection are challenging and difficult to extrapolate for predictive purposes. Alternatively, permeability, porosity and pore geometry can be measured on cores like their changes in response to mechanical, hydrothermal and geochemical constraints. However, albeit those parameters are highly correlated, relationships between the connected porosity and the permeability are complex and highly variable depending on the rock structure and mineralogy, and on the geological process involved (e.g. plastic or elastic compaction, chemical alteration, diagenesis, or microcracking; see Bernabé et al., (2003) for a recent review on the subject). This issue has been intensively studied for more than eighty years mainly in relation to oil exploitation. Several empirical or phenomenological formulas have been proposed to link permeability to the relevant pore geometry parameters, e.g. total porosity, Euclidean and fractal porosity, tortuosity, hydraulic radius and surface-to-volume ratio (e.g. Walsh and Brace, 1984; Bernabé and Revil, 1995; Revil and Cathles, 1999; Aharonov et al., 1997; Pape et al., 1999). The most usual models based on the original work of Carman (1937) establish that permeability $k$ and effective porosity $\phi$ (i.e. pore space that effectively conduces to fluid flow) are linked through a power-law relationship, $k \infty \phi^{n}$, were $n$ may be a noninteger exponent (David et al., 1994) or alternatively by a linear combination of porosity power-laws: $k \propto \sum_{i} a_{i} \phi^{n_{i}}$ (Pape et al., 1999). Asymptotically, it can be considered that the exponent $n$ varies continuously with the evolution of the 
porosity/permeability, so that $n$ is the slope of the tangent at any point of the $\log (k)$ versus $\log (\phi)$ curve. Experimental evidence indicates that a given value of $n$ is generally valid over a finite range of evolution (Bourbié and Zinszner, 1985; Mok et al., 2002). In most cases, and especially when chemical processes are involved, it is still not clear if the variation of the exponent $n$ is linked to the pore structure or to sequential activation of distinctly different alteration regimes. In this last case, the predictability of the model is poor if $n$ is not a function of $\phi$ alone or rather of a restricted number of independent measurable parameters. To overcome this problem, Aharanov et al. (1997) and Bernabé et al. (2003) proposed to relate $k$ to distinctly different porosity types. Assuming that only a fraction of the total porosity $\phi_{T}$ contributes to transport, these authors defined an effective and a non-effective porosity. Non-effective porosity, associated to areas where the fluid velocity is very low or null, such as pits and protrusions on a rough interface, or non-connected or transverse pore paths, is not taken into account for permeability calculations. Those structural parameters can theoretically be extracted from $\mathrm{C} \mu \mathrm{T}$ imaging albeit some computational steps are still challenging.

In this paper, we present the first quantitative results from a percolation experiment of a structurally heterogeneous limestone rock. The objective is to perfect an experimental and analytical method, in order to improve the understanding of the relationships between chemical reactions, microgeometry, fluid-rock interface, porosity and permeability. In the next two sections, we detail the experimental procedure consisting in three successive flow-through and $\mathrm{C} \mu \mathrm{T}$ imaging stages. The image processing used to quantify the geometrical changes of the core is also described. Then, results are analysed in terms of chemical reaction and structural control on the $k-\phi$ relationship evolution. Finally, some conclusions and perspectives are proposed.

\section{EXPERIMENTAL PROCEDURE}

\subsection{Description of Rock Sample}

The rock sample was extracted from a quarry in the Lérouville formation, a middle Oxfordian age crinoidal limestone that crops out in the Lérouville region in the Paris Basin (Meuse). The rock, a biogenic quasi-pure limestone, consists of millimetre size echinoderma fragments cemented during secondary crystallization process. The rocks is essentially composed of single crystals of calcite, but minor fraction of carbonated micritic mould is present (maximum 5\%). The micritic mould is composed of microcrystalline calcite and rare altered minerals containing $\mathrm{Fe}, \mathrm{Al}$ and $\mathrm{Si}$ (less than $1 \%$ ) that probably correspond to clays and iron hydroxide (for more details and petrographic illustrations, see Brosse et al., 2005, this issue). The occurrence of the microcrystalline calcite (low magnesian calcite), occupying some preferential flow paths, can be related to early diagenesis. Part of the microcrystalline calcite presents dissolution patterns that are attributed to the flow of meteoric water in the limestone, certainly during telogenesis (Tertiary stripping of the series). During its geological evolution the burial depth of the sediment did not reach more than few hundred metres, and the natural $P_{\mathrm{CO}_{2}}$ probably did not experience values higher than 0.04 MPa (Coudrain-Ribstein et al., 1998).

\subsection{Flow-Through Experiment}

A limestone cylindrical core of $9 \mathrm{~mm}$ diameter and $21 \mathrm{~mm}$ length is prepared to suit the experimental procedure. The core is coated with epoxy resin and fixed with silicon glue in a Teflon ${ }^{\circledR}$ sleeve to seal the core periphery. Then, the core is placed into the percolation cell. To initialize the experiment, the core is saturated under vacuum with calcite-equilibrated water. $\mathrm{CO}_{2}$-enriched water is injected at constant flow rate in the sample installed in the percolation cell with a confining pressure equal to the pressure at the sample inlet. At different stages of the reactive percolation process, the sample is removed from the cell and imaged with X-Ray $\mathrm{C} \mu \mathrm{T}$. The experiment is conducted at room temperature. Initially, three fluid bottles of distinct composition are prepared:

- deionized water then equilibrated with limestone at atmospheric partial pressure of $\mathrm{CO}_{2}\left(P_{\mathrm{CO}_{2}} \approx 10^{-4.5} \mathrm{MPa}\right)$;

- deionized water;

$-0.010 \pm 0.001 \mathrm{M} \mathrm{NaCl}$ solution prepared from reagentgrade $\mathrm{NaCl}$ diluted in deionized water.

Each of those fluids is used during a given percolation stage. A "percolation stage" of duration $\Delta t=t_{i+1}-t_{i}$ denotes a flow-through experiment with constant flow rate and constant properties of the inlet fluid. X-ray $\mathrm{C} \mu \mathrm{T}$ imaging of the core is performed before the experiment $\left(t=t_{0}\right)$ and at the end of each percolation stage $\left(t=t_{1}, t_{2}\right.$ and $\left.t_{3}\right)$. The times at the end of the first (leading to $t_{1}$ ), the second $\left(t_{2}\right)$ and the third $\left(t_{3}\right)$ reactive percolation stage are, respectively, $1 \mathrm{~h} 24 \mathrm{~min}$, $13 \mathrm{~h} 54 \mathrm{~min}$ and $22 \mathrm{~h} 24 \mathrm{~min}$ from the initial state. Inlet fluids, initially degassed, are maintained equilibrated with carbon dioxide at the partial pressure of $0.10 \pm 0.01 \mathrm{MPa}$ during the experiment. The inlet $\mathrm{pH}$ is recorded continuously in the bottle to detect potential $\mathrm{CO}_{2}$ saturation changes.

The fluid is injected into the sample at constant flow rate using a dual piston pump. The flow rate $Q$ is fixed at 100 or $300 \mathrm{~cm}^{3} \cdot \mathrm{h}^{-1}\left(2.7810^{-8}\right.$ or $\left.8.3310^{-8} \mathrm{~m}^{3} \cdot \mathrm{s}^{-1}\right)$, depending on the stage of the experiment. The hydrodynamic and compositional conditions are summarized in Table 1. Pressure is measured at the inlet in the range $0 \pm 0.00015-3 \pm 0.0015 \mathrm{MPa}$ using a computer-controlled two-stage pressure sensor system in order to increase the accuracy in the ranges $0-0.3 \mathrm{MPa}$ and $0-3 \mathrm{MPa}$ according to the value of the inlet pressure. The pressure at the outlet is set to about $0.13 \mathrm{MPa}$ using a 
calibrated back-pressure controller to avoid degassing during the experiment. The outlet $\mathrm{pH}$ and pressure are monitored. Inlet fluid is analysed prior to $\mathrm{CO}_{2}$ saturation and effluents are sampled. Samples were collected for chemical analysis of the cation concentrations, using electrophoresis and inductively coupled plasma-atomic emission spectrophotometer (ICP-AES). A schematic representation of the percolation apparatus is presented in Figure 1a.

Changes in permeability are measured throughout the percolation experiment by measuring the pressure drop $\Delta P$ between the inlet and the outlet of the sample. According to Darcy's law, the ratio of the volumetric flow rate $Q\left(\mathrm{~m}^{3} \cdot \mathrm{s}^{-1}\right)$ over the pressure difference $\Delta P$ is directly related to the permeability of the sample $k\left(\mathrm{~m}^{2}\right)$, by:

$$
k=-\frac{\mu L}{S} \frac{Q}{\Delta P}
$$

where $L$ is the length of the sample in the flow direction (m), $S$ is the section of the sample $\left(\mathrm{m}^{2}\right)$ and $\mu$ is the dynamic viscosity of the fluid (Pa.s). Permeability values are reported in $\mathrm{mD},\left(1 \mathrm{mD} \approx 0.98710^{-15} \mathrm{~m}^{2}\right)$.

\subsection{X-Ray Micro Tomography}

The microgeometry of the core is characterised throughout the experiment using X-ray microtomography. The X-ray linear attenuation coefficient of a sample depends on its chemical composition and on the energy of the X-ray beam, and is proportional to the rock assemblage density. The tomography apparatus installed at the ID19 beamline of the European Synchrotron Radiation Facility (ESRF, Grenoble, France) takes advantage of the homogeneous, parallel, monochromatic, and highly coherent very high photon flux produced by the synchrotron. So, the scanning of $1 \mathrm{~cm}$ thick cylindrical core of carbonate is tractable. The detection device is composed of a shutter controlling the exposure time, an $\mathrm{X}$-ray/visible light converter, an optical system and an adapted detector (14-bit dynamic CCD (for charged coupled device) camera with a 2048 x 2048 pixel chip (FReLoN camera). With the selected optics, the pixel size is $4.91 \mu \mathrm{m}$. The core is fixed on a mechanical bench; all scans are perpendicular to the cylinder axis. The incident beam illuminates the entire diameter of the core in order to decrease as much as possible the diffusion effect and the resulting reconstruction artefacts. As the entire core cannot be imaged in one run, the beam is adjusted to image the part close to the fluid injection side of the core (at about $1 \mathrm{~mm}$ from the inlet surface). A total of 1200 radiographies, taken from 0 to 180 degrees with a 0.15 angular degrees increment, are required to obtain high quality images (Fig. 1 b). An efficient back projection algorithm is used to reconstruct the 3D volume structure from the 2D radiographies. Here, HST (for high speed tomography) software based on Fourier inversion is used (Hammersley, 2001). Radiographies are filtered before the reconstruction in order to eliminate the random noise due to high energy diffracted photons that may go through the lead shield of the camera.

Four scans are taken: at the initial state $\left(t_{0}\right)$, and after the three stages of the reactive percolation $\left(t_{1}, t_{2}\right.$ and $\left.t_{3}\right)$. Results presented here correspond to four volumes $V_{t 0}, V_{t 1}, V_{t 2}$ and $V_{t 3}$ of $2048 \times 2048 \times 1405$ voxels corresponding to the common field of view of the sample imaged at $t_{0}, t_{1}, t_{2}$ and $t_{3}$, respectively. Because the linear X-ray attenuation coefficient is a function of elemental composition of the object, the absorption maps can be directly related to the chemical distribution in the sample. For data manipulation, the data sets

TABLE 1

Summary of fixed physical parameters for plug-flow experiment stages

\begin{tabular}{|c|c|c|c|c|}
\hline & $\begin{array}{l}\text { Initial } \\
\left(t=t_{0}\right)\end{array}$ & $\begin{array}{c}\text { Percolation } 1 \\
\left(t_{0}<t \leq t_{1}\right)\end{array}$ & $\begin{array}{c}\text { Percolation } 2 \\
\left(t_{1}<t \leq t_{2}\right)\end{array}$ & $\begin{array}{c}\text { Percolation } 3 \\
\left(t_{2}<t \leq t_{3}\right)\end{array}$ \\
\hline Flow rate $Q\left(\mathrm{~cm}^{3} \cdot \mathrm{h}^{-1}\right)$ & & 300 & 300 & 100 \\
\hline Duration $t(\mathrm{~h})$ & & $1 \mathrm{~h} 24 \mathrm{~min}$ & $12 \mathrm{~h} 31 \mathrm{~min}$ & $8 \mathrm{~h} 30 \mathrm{~min}$ \\
\hline $\begin{array}{l}\text { Inlet fluid composition } \\
P_{\mathrm{CO}_{2}}\end{array}$ & & $\begin{array}{c}\text { Deionized water equilibrated } \\
\text { with carbonated rock } \\
\text { at atmospheric } P_{\mathrm{CO}_{2}} \\
0.10 \pm 0.01 \mathrm{MPa}\end{array}$ & $\begin{array}{l}\text { Deionized water } \\
0.10 \pm 0.01 \mathrm{MPa}\end{array}$ & $\begin{array}{c}\text { Deionized water } \\
+0.01 \mathrm{M} \mathrm{NaCl} \\
0.10 \pm 0.01 \mathrm{MPa} \\
\end{array}$ \\
\hline $\mathrm{pH}$ inlet & & $4.7 \pm 0.1$ & $3.9 \pm 0.1$ & $3.8 \pm 0.1$ \\
\hline $\mathrm{pH}$ outlet & & $5.6 \pm 0.2$ & $5.6 \pm 0.2$ & $5.2 \pm 0.1$ \\
\hline Average $\Delta C a\left(\mathrm{~mol} \cdot \mathrm{l}^{-1}\right)$ & & $\begin{array}{c}0.3210^{-3} \\
\pm 0.1010^{-3}\end{array}$ & $\begin{array}{c}0.4910^{-3} \\
\pm 0.0510^{-3}\end{array}$ & $\begin{array}{c}1.0710^{-3} \\
\pm 0.0710^{-3}\end{array}$ \\
\hline 3D Imaging & $\mathrm{x}$ & $\mathrm{x}$ & $\mathrm{x}$ & $\mathrm{x}$ \\
\hline
\end{tabular}



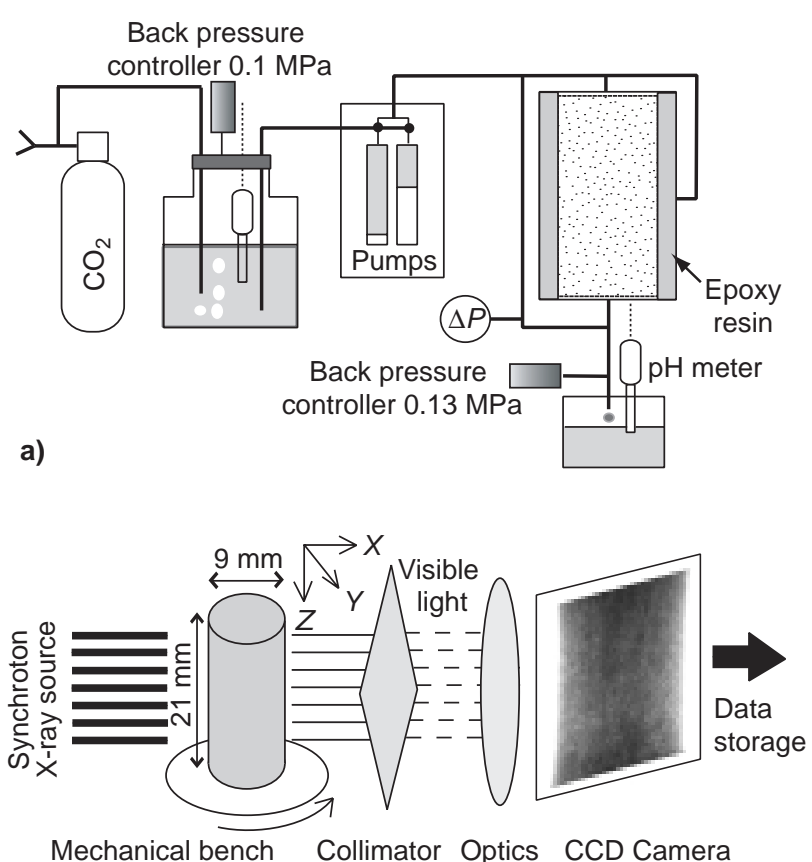

b)

Figure 1

a) a schematic description of the experimental setup; and b) of the X-ray microtomography setup.

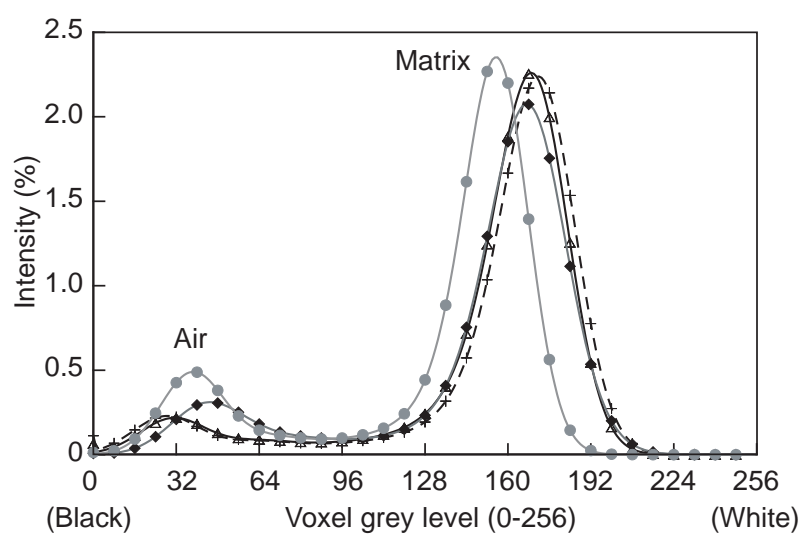

Figure 2

Intensity values of renormalized histograms of the core showing air and matrix peaks, before injection $\left(t_{0}\right)$ (joined open black triangles), after $1 \mathrm{~h} 24 \mathrm{~min}\left(t_{1}\right)$ (joined grey crosses), after $13 \mathrm{~h} 54 \mathrm{~min}\left(t_{2}\right)$ (joined black diamonds), after $22 \mathrm{~h} 24 \min \left(t_{3}\right)$ (joined grey circles).

(coded in real number, i.e. 32 bits) produced by the reconstruction process are converted into greyscale $3 \mathrm{D}$ images ( 0 to 255 ) coded in one byte ( 8 bits). By convention, dark voxels correspond to low density phases (voids), whereas light voxels denote high density phases (matrix).
As we deal with several data sets of the same core being imaged at increasing times, it is important to make sure that the different volumes are comparable between them even if $\mathrm{X}$-ray beam intensity fluctuation exists. Assuming that the composition and the density of the porous phase and the massive crystals are unchanged, difference in the X-ray attenuation is attributed to variation in the X-ray beam properties or to uncontrolled alteration in the conditions of acquisition. The histograms of grey level distribution are then renormalized to adjust the minimum and maximum values at the fixed values determined for the first 3D image, using a linear interpolation procedure (Fig. 2). All the voxels having a real value smaller than the minimum are set to 0 and all the voxels having a real value larger than the maximum are set to 255 .

\section{RESULTS AND DISCUSSION}

\subsection{Dissolution Patterns}

Figure 3 displays cross-sections of the sample observed in microtomography at the initial state, and shows the pore structure evolution after each stage of the percolation experiment. Note that the different cross-sections are not exactly superimposable because of uncertainties on the core position relating to the camera between the different imaging steps (see Section 2.2). Nevertheless, we can observe clearly that both the porosity and the connectivity globally increase from stage 2 .

Figure 4 presents the differences between initial and final morphology. In the experiment, the initial rough contours of the grains are progressively smoothed. At the grain scale, the roughness of initial serrated grains decreases; syntaxial rough cement also disappears. The porous channel contours tend to be rounded. We also presume that the echinoderma monocrystals dissolution may occur preferentially along some crystallographic axis, as shown in Figure 4: some initially round echinoderma fragments tend to dissolve along some angular and planar faces. Nevertheless, the roughness of some micro porous grains initially smoothly coated with recrystallized cement may increase locally as cement dissolves; then, the intragranular porosity of echinoderma is exposed to the moving fluid (Fig. 4).

\subsection{Quantification of Pore Structure and Surface Evolution}

The next step of image processing is to replace the different volumes in the reference frame. Indeed, as the core is removed from its support between two image acquisitions, it never falls exactly in the same position, and some translation and rotation exist between the different images. Rigid transformation has to be applied to the different images. Theoretically, control voxels corresponding to recognizable unaltered grains can be used to determine this rigid transformation. Practically, it is very 

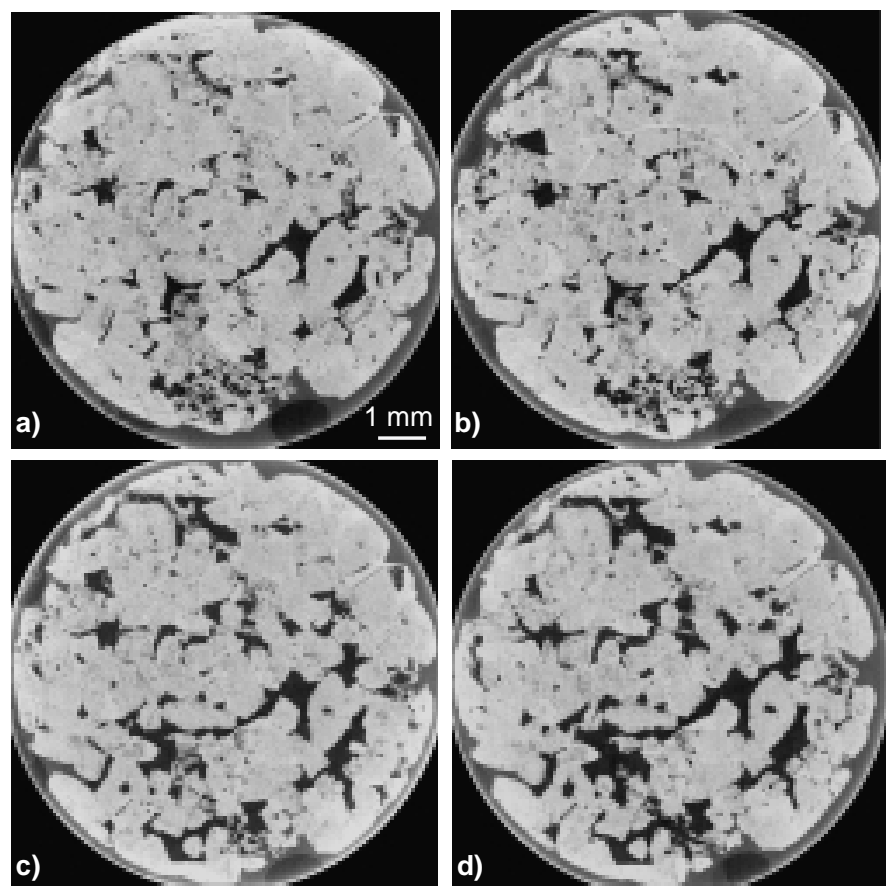

Figure 3

Cross-sectional images of the limestone microgeometry obtained by X-ray micro-tomography following its dissolution in the plug-flow apparatus, at a) $t_{0}$ (initial); b) $t_{1}$ (after $1 \mathrm{~h} 24 \mathrm{~min}$ ); c) $t_{2}$ (after $13 \mathrm{~h} 54 \mathrm{~min}$ ); d) $t_{3}$ (after $22 \mathrm{~h} 24 \mathrm{~min}$ ).
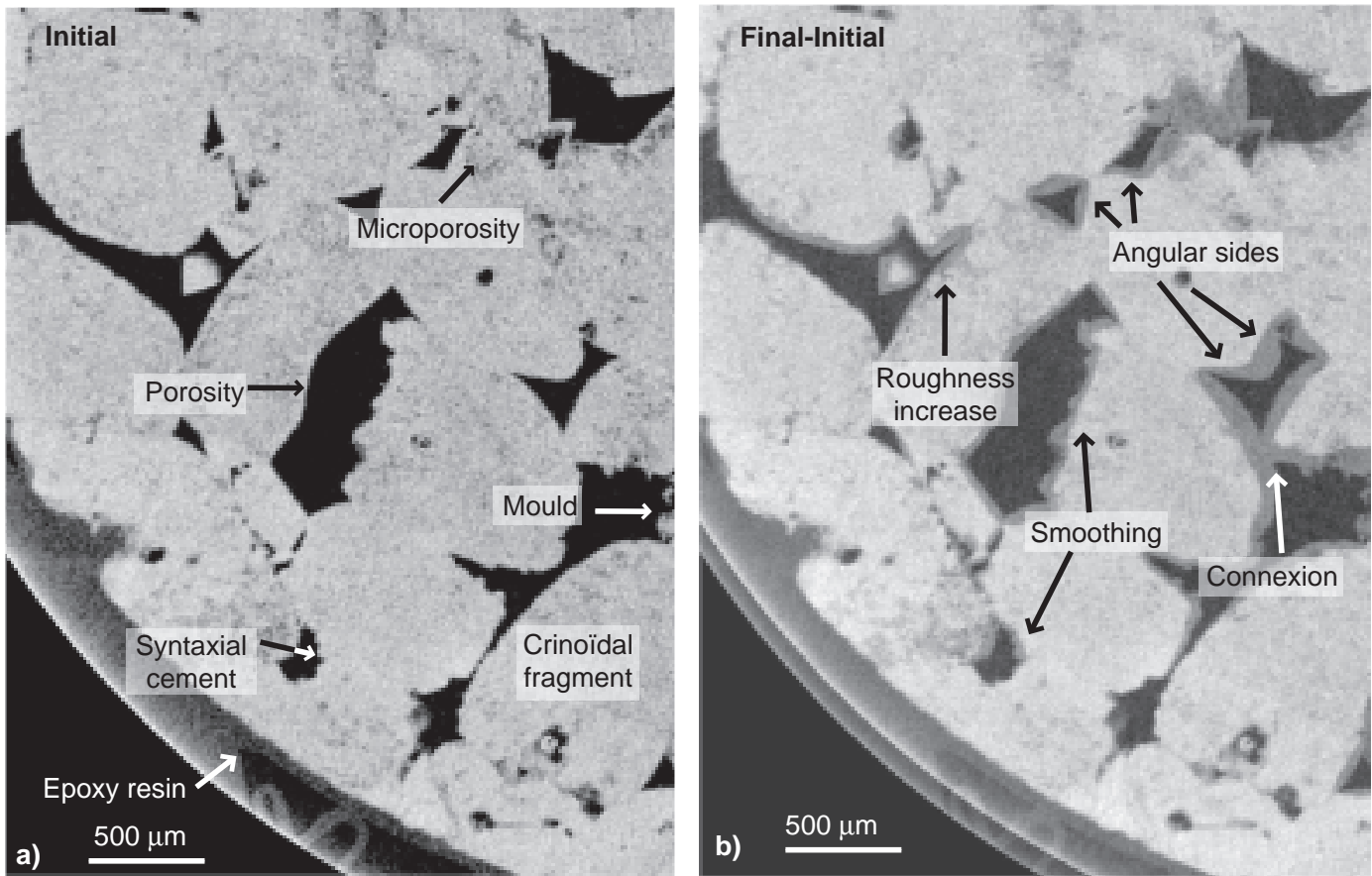

Figure 4

a) cross-sectional image obtained by X-ray micro-tomography at initial state of experiment; (dark) porosity, (high grey level) matrix. b) difference in cross-sectional images between final and initial state of experiment; (dark) initial porosity, (high grey level) matrix at final state, (low grey level) dissolved matrix (i.e. porosity increase). 


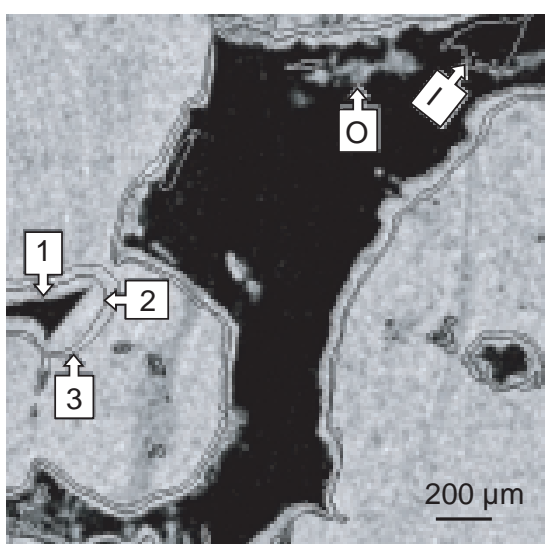

Figure 5

Visualisation of the fluid-solid interface $I_{f s}$ in the course of the experiment. The grey level of the $(2 \mathrm{~mm})^{2}$ background image corresponds to the initial state $\left(t_{0}\right)$. The lines marked " 1 " (white), "2" (dark) and "3" (dark) correspond respectively to the fluid-solid interface position at $t_{1}, t_{2}$, and $t_{3}$. It appears clearly that during the first stage of the percolation experiment, the modifications mainly concern the "micritic phase" with dissolution and particle mobilization: a particle that went out the pore is marked " $\mathrm{O}$ " and a particle that came into the pore is marked "I". difficult to localize those control voxels with enough precision. Using a large number of points in association with a least square fitting procedure permits the first two volumes $V_{t 0}$ and $V_{t 1}$ to be handled, but the two other volumes are noisy because of difficulties during acquisition, and the results obtained using this approach are not considered satisfactory. Alternatively, an improved registration method is under to treat the complete series of 3D volumes. In this paper, we only consider four small sub-volumes $S V_{t i}$ of $(2 \mathrm{~mm})^{3}$ in order to test a new approach to quantify the volume and surface evolutions.

The four sub-volumes, $S V_{t 0}$ to $S V_{t 3}$, corresponding to subvolumes at times $t_{0}$ to $t_{3}$, are registered in $3 \mathrm{D}$ and then it is possible to visualise the evolution of the fluid-solid interface $\left(I_{f s}\right)$ on cross-sections (Fig. 5). This figure clearly demonstrates that it is possible to follow accurately the evolution of the fluid-solid interface $I_{f s}$ during the percolation experiment.

To facilitate the quantification of this evolution, the information contained in the four sub-volumes (a value between 0 and 255 for each voxel of $S V_{t 0}$ to $S V_{t 3}$ ) is compacted in a single one noted $S V_{E}$. The value affected to a voxel of $S V_{E}$ is calculated by the following procedure:

- For each 3D sub-volume, a threshold value is selected (see Section 2.3 for more details). A voxel with a value above a) For each voxel of $S V_{E}$ :

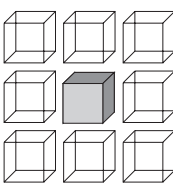

$S V_{t 3}$ Pore $\Rightarrow 0$

$S V_{t 2}$ Pore $\Rightarrow$

$S V_{t 1}$ Solid $\Rightarrow$

$S V_{\text {to }}$ Solid $\Rightarrow$

b)

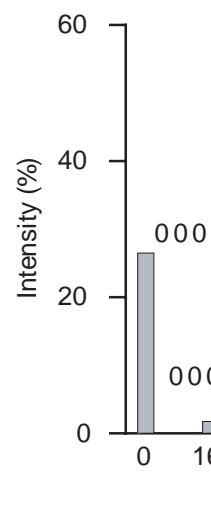

1 byte $=8$ bits

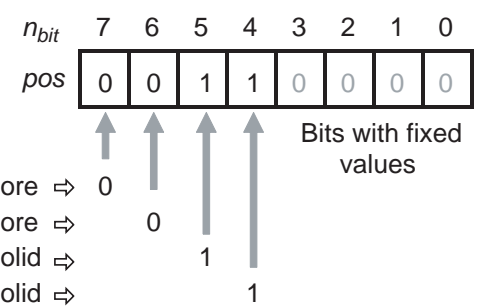

Figure 6

a) procedure used to condense in one byte the information on the evolution of each voxel of the considered sub volume. The voxel (or byte) has a value equal to: $\sum_{\text {byte }} \operatorname{pos} \times 2^{\text {nbit }}$, where pos indicates the bit position ( 0 or 1$)$ and $n_{\text {bit }}$ the bit number. In the presented example, the voxel has a value of $2^{5}+2^{4}=48$. This voxel was solid in the two first stages, dissolved during the second stage of experiment and consequently, in the pore volume in the last two stages. b) histogram of the values of each voxel of sub volume $S V_{E}$. 
this threshold is considered as a matrix volume voxel; otherwise it is a pore volume voxel.

- For each voxel of $S V_{E}$ we consider the value of the corresponding voxel of $S V_{t 3}$. If the voxel value corresponds to the matrix, the highest bit (bit number $\left(n_{b i t}\right) 7$ ) of the byte associated to the voxel is set to one; if not, it is set to zero.

- The process is repeated for $S V_{t 2}$ to $S V_{t 0}$ to define the value of the bit numbers 6 to 4 for the byte associated to each voxel of $S V_{E}$.

- The four last bits ( $n_{b i t} 3$ to 0 ) of each byte in the volume $S V_{E}$ are set to zero.

At the end of the procedure (Fig. $6 a$ ), each voxel of $S V_{E}$ has one of the 16 possible values. Each of those values corresponds to a unique scenario where the voxel is successively in the solid or the pore volume at the four different stages. The histogram of the values at the $S V_{E}$ voxels is given in Figure $6 \mathrm{~b}$. It reveals that 6 separate values of the 16 possible correspond to $99.4 \%$ of the voxels. Those values are indicated in Figure $6 \mathrm{~b}$ by their code on the four highest bit numbers. The corresponding scenarios are described in Table 2.
To continue towards quantification, the sub-volume $S V_{E}$ is divided in 6 regions ( $\mathrm{R} 1$ to R6) corresponding to the 6 classes of voxels described in Table 2 . The residuals voxels $(0.6 \%$ corresponding to the 10 other values) are distributed between R4 (48), R5 (112) and R6 (240) depending of their values. Each voxel being labelled, it is easy to visualise (Fig. 7) and to quantify the volume differences between the different stages. From the labelled data set, the surface separating each region can be evaluated (Table 3). From Table 3, an estimation of $I_{f s}$ can be calculated for each stage of the evolution (Table 4).

The shifting of fluid-rock interface in the course of the experiment is not uniform as illustrated in Figure 5. During the first short percolation experiment, we did not observe any noticeable change at the fluid-rock interface, excepted particle displacement in the porous network. The shifting of $I_{f s}$ is more important in the narrow pore (Fig. 5, on the left). Table 4 displays a small decrease of the fluid-solid interface during the first stage of experiment, followed by a substantial decrease during the second stage and finally by another small

TABLE 2

Classification procedure of the sub-volume evolution, $S V_{E}$

\begin{tabular}{|c|c|c|c|}
\hline Value & Code & Label & Scenario \\
\hline 0 & 0000 & $\mathrm{R} 1$ & Voxel that belongs to pore volume from the beginning to the end \\
\hline 16 & 0001 & $\mathrm{R} 2$ & $\begin{array}{l}\text { Voxel that was solid at } t_{0} \text { and has been dissolved or displaced during the } 1 \text { st stage } \\
\text { of the reactive percolation }\end{array}$ \\
\hline 32 & 0010 & $\mathrm{R} 3$ & $\begin{array}{l}\text { Voxel that was in the pore volume at } t_{0} \text {, has been occupied by a moving particle at } t_{1} \\
\text { and dissolved or displaced during the } 2 \text { nd reactive percolation stage }\end{array}$ \\
\hline 48 & 0011 & R4 & Solid voxel dissolved during the 2 nd reactive percolation stage \\
\hline 112 & 0111 & R5 & Solid voxel dissolved during the 3rd reactive percolation stage \\
\hline 240 & 1111 & R6 & Voxel that belongs to the solid from the beginning to the end \\
\hline
\end{tabular}

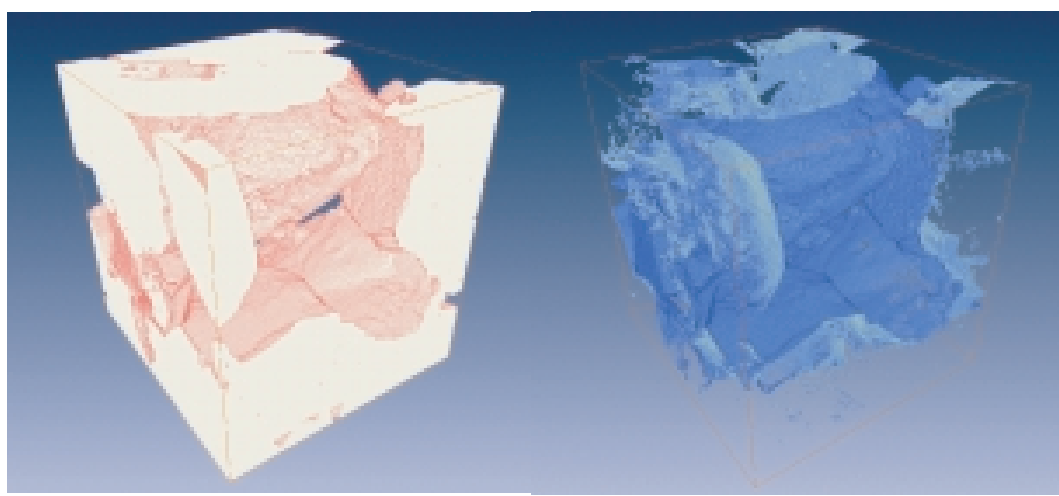

Figure 7

From the sub volume $S V_{E}$, visualisation of the region R6 (left), corresponding to the voxels that belong to the solid from the beginning to the end, and of the region R5 (right), corresponding to the solid voxels dissolved during the last reactive percolation experiment (stage 3). The sides of the cube are $2 \mathrm{~mm}$. 
decrease during the last stage. Examining carefully the expression of $I_{f s}$ given on Table 4 (column 3) it can be seen that some surface elements are in common between two stages (for instance $S_{1-5}, S_{1-6}, S_{2-5}$ and $S_{2-6}$ between stage 2 and 3). Those unchanged areas (Table 4, column 4) correspond to surface elements belonging to $I_{f s}$ where no noticeable modification has been detected. It may correspond to pores where the fluid is stagnant (no significant dissolution). Obviously, this part of $I_{f s}$ will not contribute to the effective reactive surface $S r$ at the macroscopic scale.

TABLE 3

Calculated area of the fluid-rock surfaces between the different regions

\begin{tabular}{c|c|c}
\hline Surface & Between regions & Area $\left(\mathbf{1 0}^{-\mathbf{6}} \mathbf{~ m}^{\mathbf{2}}\right)$ \\
\hline$S_{1-2}$ & R1-R2 & 4.05 \\
$S_{1-3}$ & R1-R3 & 1.84 \\
$S_{1-4}$ & R1-R4 & 17.49 \\
$S_{1-5}$ & R1-R5 & 2.04 \\
$S_{1-6}$ & R1-R6 & 2.17 \\
$S_{2-3}$ & R2-R3 & 0.18 \\
$S_{2-4}$ & R2-R4 & 2.68 \\
$S_{2-5}$ & R2-R5 & 0.72 \\
$S_{2-6}$ & R2-R6 & 0.10 \\
$S_{3-4}$ & R3-R4 & 0.90 \\
$S_{3-5}$ & R3-R5 & 0.10 \\
$S_{3-6}$ & R3-R6 & 0.12 \\
$S_{4-5}$ & R4-R5 & 12.00 \\
$S_{4-6}$ & R4-R6 & 3.93 \\
$S_{5-6}$ & R5-R6 & 13.90 \\
\hline
\end{tabular}

\subsection{Porosity Changes}

As the core is almost completely composed of calcite, the overall rate of dissolution $r\left(\mathrm{~mol} \cdot \mathrm{s}^{-1}\right)$ is accurately evaluated by the calcium amount removed by the percolating fluid throughout the sample:

$$
r=\frac{\delta n_{\text {calcite }}}{\delta t}=\Delta C a \times Q
$$

where $n_{\text {calcite }}$ is the number of mole of dissolved calcite, $t$ the time (s), $\Delta C a$ is the variation in calcium concentration between the inlet and the outlet of the sample $\left(\mathrm{mol} \cdot \mathrm{m}^{-3}\right)$ and $Q$ is the volumetric flow rate $\left(\mathrm{m}^{3} \cdot \mathrm{s}^{-1}\right)$.
The sample-averaged total porosity $\left(\phi_{T}\right)$ change is given by:

$$
\frac{\delta \phi_{T}}{\delta t}=-\frac{1}{V_{T}} \times \frac{\delta V_{\text {calcite }}}{\delta t}=-\frac{Q \times v_{\text {calcite }}}{V_{T}} \times \frac{\delta(\Delta C a)}{\delta t}
$$

with $\delta V_{\text {calcite }}$ the variation in volume of calcite $\left(\mathrm{m}^{3}\right), V_{T}$ the volume of the sample $\left(\mathrm{m}^{3}\right)$ and $v_{\text {calcite }}$ the molar volume of calcite $\left(\mathrm{m}^{3} \cdot \mathrm{mol}^{-1}\right)$.

The total porosity $\phi_{T}$ at time $t$ is obtained by integration of Equation (3):

$$
\phi_{t}=\phi_{0}+\frac{Q \times v_{\text {calcite }}}{V_{T}} \int_{t o}^{t i} \Delta C a \mathrm{dt}
$$

where $\phi_{0}$ denotes the initial sample porosity.

Conversely, total porosity can be determined from the $\mathrm{C} \mu \mathrm{T}$ data by discriminating the voids from the solid phase. Different methods can be used to identify each voxel as belonging to a pore or a grain. Here, a simple thresholding is applicable because distributions of the values corresponding to the pores and the rock matrix are well separated on the histograms (Fig. 2). The determination of the appropriate threshold is essential in this approach. However, the pore and the rock matrix phases are not defined by a single value in the grey scale; for a given material, the distribution of the attenuation coefficient is spread out in the histogram, resulting of inherent noise of the imaging technique and of finite resolution effects. For the different peaks in the histogram, it is nevertheless possible to consider that the true linear X-ray attenuation coefficients of the different materials are located at the maximum peak values. For a rock made of only two materials (bimodal histogram), a good estimate of the threshold can be the arithmetic mean of the two values for which intensity is maximum in the histogram. The presence of the micritic mould slightly alters the shape of the histograms and better estimates of the threshold values have been obtained by visual inspection of several sections on which isolines have been drawn (like in Fig. 5). The threshold value is chosen equal to $95,95,99$ and 92 for $V_{t 0}$ to $V_{t 3}$, respectively. The porosity is equal to the sum of the voxels of count lower than the threshold value divided by the total number of voxels considered. Because the external part of the sample is irregularly coated with epoxy resin and or silicone sealing paste, it

\section{TABLE 4}

Calculated reactive and non-reactive areas of the fluid-rock surfaces at initial state $\left(t_{0}\right)$ and at the end of each stage of the percolation experiment $\left(t_{1}\right.$ to $\left.t_{3}\right)$

\begin{tabular}{c|c|c|c}
\hline Time & Fluid-solid interface & $\begin{array}{c}\text { Area } \\
\left(\mathbf{1 0}^{-\mathbf{6}} \mathbf{m}^{\mathbf{2}}\right)\end{array}$ & $\begin{array}{c}\text { Unchanged area } \\
\left(\mathbf{1 0}^{-\mathbf{6}} \mathbf{m}^{\mathbf{2}}\right)\end{array}$ \\
\hline$t_{0}$ & $S_{1-2}+S_{1-3}+S_{1-4}+S_{1-5}+S_{1-6}+S_{2-3}+S_{3-4}+S_{3-5}+S_{3-6}$ & 28.87 & \\
\hline$t_{1}$ & $S_{1-3}+S_{1-4}+S_{1-5}+S_{1-6}+S_{2-3}+S_{2-4}+S_{2-5}+S_{2-6}$ & 27.21 & 23.71 \\
\hline$t_{2}$ & $S_{1-5}+S_{1-6}+S_{2-5}+S_{2-6}+S_{3-5}+S_{3-6}+S_{4-5}+S_{4-6}$ & 21.18 & 5.02 \\
\hline$t_{3}$ & $S_{1-6}+S_{2-6}+S_{3-6}+S_{4-6}+S_{5-6}$ & 20.22 & 6.32 \\
\hline
\end{tabular}


is not exposed to the dissolution process; and so the porosity calculation is performed on a cylinder of $8.84 \mathrm{~mm}(1800$ voxels) diameter and $6.9 \mathrm{~mm}$ height (1405 voxels) that corresponds to the fluid saturated part of the sample. Porosity values for initial state and after the different experimental stages are reported in Table 5. We also computed the porosity change along the flow direction ( $z$ axis), by calculating porosity for each cross section (Fig. 8).

The porosity of the rock was first measured by $\mathrm{Hg}$ injection on a sample volume of about $1 \mathrm{~cm}^{3}$ adjacent to the core. This yielded a value of $14.1 \%$ which is close to the average value of $15 \%$, measured by the triple-weighting technique on several cores sampled in the same formation. However, the porosity value may be less, depending on the intensity of the secondary crystallisation process. Conversely, porosity evaluated before the percolation experiment from the $\mathrm{C} \mu \mathrm{T}$ (volume $V_{t 0}$ ) is $10.8 \%$ with a precision of $\pm 0.5 \%$. The porosity distribution along the core axis is homogeneous with a weak spatial variation (see Fig. 8). This value is used as reference for the core porosity $\phi_{0}$ before the experiment. The different values of porosity changes are calculated by three different methods:

- core-scale porosity estimated from $\mathrm{Ca}$ concentration removed (Eq. (4));

- core-scale porosity measured on the $\mathrm{C} \mu \mathrm{T}$ volumes $\left(\mathrm{V}_{t i}\right)$;

- microscale porosity calculated on sub-volume extracts $\left(S V_{t i}\right)$.

The evolution of porosity during the percolation experiment is reported Table 5 .

Estimations from chemical measurement give an overall increase of core-scale porosity of $0.3,4.3$ and $2.2 \%$ during stage 1 , stage 2 and stage 3 , respectively. The initial porosity of the $8 \mathrm{~mm}^{3}$ sub-volume $S V_{t 0}$ is $27.3 \%$, but misrepresentative of the porosity of the rock, in view of the size of echinoderma fragments. During the first percolation experiment,
$1.7 \%$ of the volume is removed, but $1.1 \%$ of solid particles appeared in $S V_{t 1}$. The global porosity change in this region is thus only $0.6 \%$. Porosity increases by $8.4 \%$ and $4.6 \%$ during stage 2 and stage 3 , respectively, without any noticeable contribution of particles.

We observe in Figure 8 that the distribution of porosity at $t_{0}$ is variable along the flow axis. The initial average porosity $\phi_{0}$ of the $3 \mathrm{D}$ volume $V_{t 0}$ is equal to $10.8 \%$, with a standard deviation $\sigma_{\phi 0}$ of 1.8. During the dissolution, the porosity does not increase uniformly according to the initial porosity value and to the distance to the inlet of the sample. The porosity increases more in the area where initial porosity is higher. The standard deviation of porosity distribution increases, $\sigma_{\phi V t 2}=2.7$ and $\sigma_{\phi V t 3}=2.8$ after stages 2 and 3, respectively $\left(\phi_{V t 2}=15.3 \% ; \phi_{V t 3}=18.8 \%\right)$. The higher the initial porosity the more it increases in the course of dissolution (whereas the dissolution is more important in narrow pore paths, see Fig. 5). That can be easily related to the pore size: the wider a pore, the larger the surface exposed to the acidic fluid and the more the porosity will increase during rock/fluid interface displacement. Results show that the porosity increase is not uniform along the flow axis; moreover, the dissolution is more marked near the inlet of the core (Fig. 8). The porosity difference between final and initial state near the inlet of the sample is $9.30 \%$, whereas it is only $6.73 \%$ near the outlet.

\subsection{Rate of Dissolution}

Differences in $\mathrm{Ca}$ concentration and $\mathrm{pH}$ between core outlet and inlet can be directly related to the progress of the chemical reaction of calcite dissolution. The differences in $\mathrm{pH}$ values (Table 1) between the three stages are linked to the composition of the inlet solution. Values of $\mathrm{pH}$ are almost invariant (Table 1), but a weak decrease, attributed to an uncontrolled slow increase of the $P_{\mathrm{CO}_{2}}$ in the input solution, is recorded. The calcium concentration values measured at

TABLE 5

Summary of chemical and physical results for initial state and at the end of each plug-flow experiment stage

\begin{tabular}{|c|c|c|c|c|}
\hline & $\begin{array}{l}\text { Initial } \\
\left(t=t_{0}\right)\end{array}$ & $\begin{array}{l}\text { Percolation } 1 \\
\quad\left(t=t_{1}\right)\end{array}$ & $\begin{array}{l}\text { Percolation } 2 \\
\quad\left(t=t_{2}\right)\end{array}$ & $\begin{array}{c}\text { Percolation } 3 \\
\left(t=t_{3}\right)\end{array}$ \\
\hline Total porosity $\phi \%$ (chemistry) & 10.8 & 11.1 & 15.0 & 17.1 \\
\hline Porosity difference & & +0.3 & +3.9 & +2.1 \\
\hline Volume $V_{t i}$ (tomography) & $V_{t 0}$ & $V_{t 1}$ & $V_{t 2}$ & $V_{t 3}$ \\
\hline Porosity $\phi \%$ & 10.8 & 11.3 & 15.3 & 18.8 \\
\hline Porosity difference & & +0.5 & +4.0 & +3.5 \\
\hline Sub-volume $S V_{t i}$ (tomography) & $S V_{t 0}$ & $S V_{t 1}$ & $S V_{\mathrm{t} 2}$ & $S V_{t 3}$ \\
\hline Porosity $\phi \%$ & 27.7 & 28.3 & 36.7 & 41.3 \\
\hline Porosity difference & & $+0.6(+1.7-1.1)$ & +8.4 & +4.6 \\
\hline Permeability $k\left(\mathrm{~m}^{2}\right)$ & 40 & 300 & $>5000$ & - \\
\hline
\end{tabular}


the output are variable during the experiment (Table 1). Assessing the influence of the input fluid composition (i.e. ionic strength, $\mathrm{Ca}$ initial concentration, etc.) on the dissolution rate is tricky because flow velocity (i.e. the resident time of the fluid in the core) was variable during the experiment (100 or $300 \mathrm{~cm}^{3} \cdot \mathrm{h}^{-1}$ ), and because the sampling frequency was relatively low.

The resident time of fluid in the core is: $t_{R}=L / u$, where $L$ is the core length $(\mathrm{m}), u$ the mean flow rate $\left(\mathrm{m} \cdot \mathrm{s}^{-1}\right) ; t_{R}$ is short compared to the kinetics of the calcite dissolution process, and the solution remains very undersaturated (the saturation index $\Omega$ of calcite is about $10^{-3}$ ). Because the resident time is higher for stage 3 at $100 \mathrm{~cm}^{3} \cdot \mathrm{h}^{-1}$ than for the others stages at $300 \mathrm{~cm}^{3} \cdot \mathrm{h}^{-1}$, the progress of the chemical reaction is more important, explaining that $\mathrm{Ca}$ concentration is about 3 times higher for stage 3 than for stage 1 and stage 2 (Table 1).

It is generally admitted that the equation describing the rate $\left(\mathrm{mol} \cdot \mathrm{s}^{-1}\right)$ of calcite dissolution is (Lasaga, 1981): $r=S r \cdot k \cdot(1-\Omega)^{\alpha}$, where $S r$ is the reactive surface of the mineral $\left(\mathrm{m}^{2}\right), k$ is global kinetic rate constant of dissolution $\left(\mathrm{mol} \cdot \mathrm{m}^{-2} \cdot \mathrm{s}^{-1}\right), \Omega$ denotes the calcite saturation index, and $\alpha$ is an exponent. Far from equilibrium, $k$ can be described (Plummer et al., 1978) by: $k=k_{1} a_{\mathrm{H}^{+}}+k_{2} a_{\mathrm{H}_{2} \mathrm{CO}_{3} *}+k_{3} a_{\mathrm{H}_{2} \mathrm{O}}$, where $a_{i}$ denotes the activity of the specie $i, k_{1}, k_{2}$ and $k_{3}$ are kinetic rate constants equal to $5.1210^{-1}, 3.4510^{-4}$ and $1.1910^{-6} \mathrm{~mol} \cdot \mathrm{m}^{-2} \cdot \mathrm{s}^{-1}$ respectively at $25^{\circ} \mathrm{C}$. Far from equilibrium and at relatively low $\mathrm{pH}($ e.g. $\mathrm{pH}<4.5)$, the rate of dissolution is $\mathrm{pH}$ dependent. Because $\mathrm{H}^{+}$are consumed as the fluid is flowing along the core, the term $k_{1} a_{\mathrm{H}^{+}}$and therefore $r$ decreases progressively and dissolution occurs preferentially near the inlet of the sample, as observed in Figure 8. Indeed, porosity measurements using $\mathrm{C} \mu \mathrm{T}$ are performed on the part of the core close to the inlet; so that they do not represent the core scale porosity average and values are expected to be higher than the porosity measured from the chemical analysis.

A basic concept in chemical kinetics is that chemical reactions result from a set of serial chemical and physical processes, including:

1 diffusion of the reactants through solution to the solid surface;

2 adsorption of the reactants at the reaction site;

3 chemical reaction that may involve several stages, including the hydration of species;

4 desorption of the products away from the reaction site;

5 diffusion of the products away from the surface to the solution.

In most natural systems, the surface reactions at the mineral-fluid interface (steps 2, 3,4) are assumed to control the kinetics of the reaction. But for calcite at low $\mathrm{pH}$, the chemical reaction is so fast that competition exists between the surface reactions (steps 2, 3 and 4) and the diffusive transport of the reacting species (steps 1 and 5) at the solid-liquid interface (e.g. Rickard and Sjöberg, 1983). Moreover in moving solutions, advective transport is substantially faster than molecular diffusion, so the renewal of fluid is enhanced near the interface, and the dissolution rate increases with the fluid velocity.

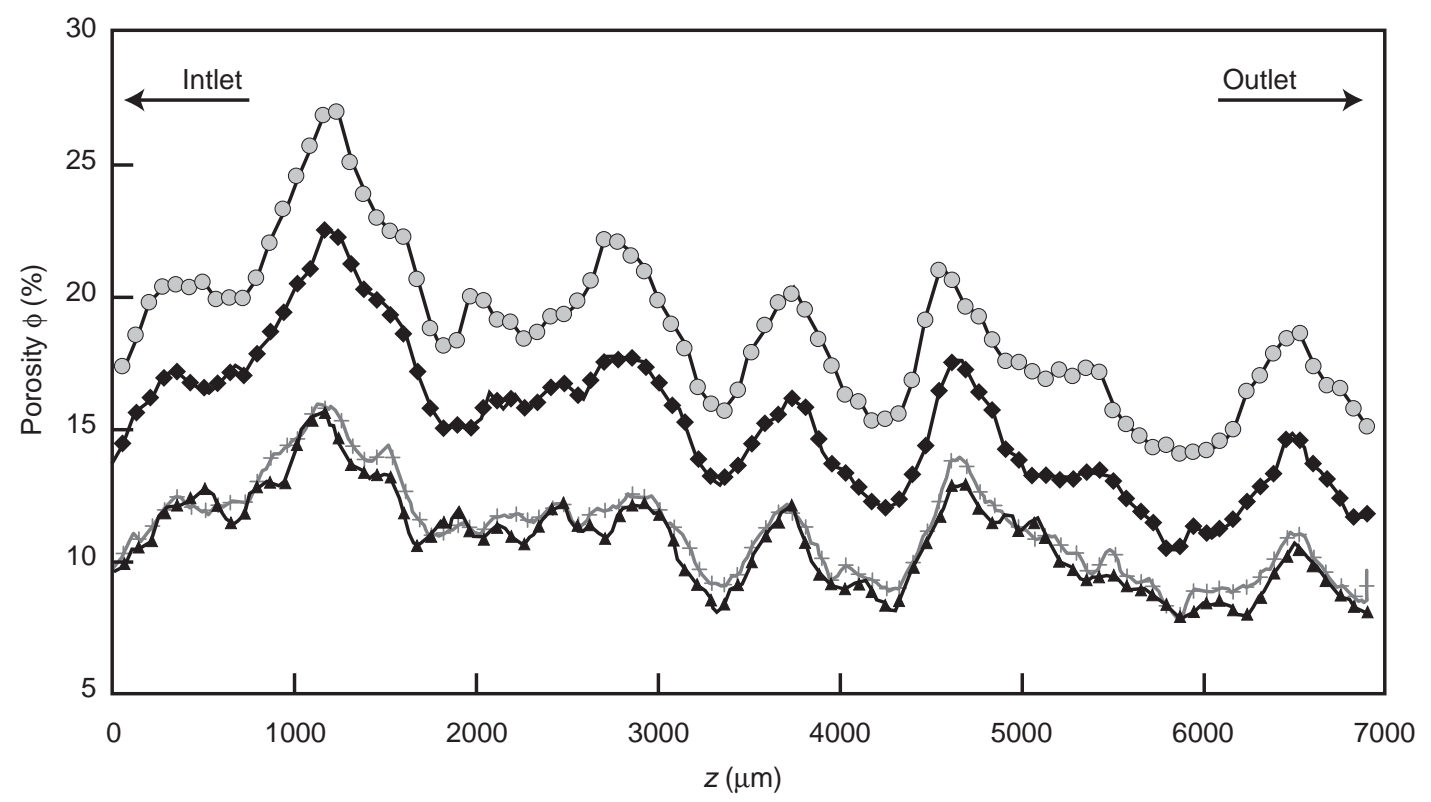

Figure 8

Plot of average porosity along the flow direction axis $z$, at times $t_{0}, t_{1}, t_{2}$ and $t_{3}$ : before injection (joined open black triangles), after $1 \mathrm{~h} 24 \mathrm{~min}$ (joined grey crosses), after $13 \mathrm{~h} 54$ min (joined black diamonds), after $22 \mathrm{~h} 24 \mathrm{~min}$ (joined grey circles). 
According to Darcy's law the average flow rate is: $u=U / \phi$, where $U$ is the filtration flow rate $\left(\mathrm{m} \cdot \mathrm{s}^{-1}\right)$. The average flow rate is $1.3910^{-3} \mathrm{~m} \cdot \mathrm{s}^{-1}$ for stages 1 and 2 at $300 \mathrm{~cm}^{3} \cdot \mathrm{h}^{-1}$, and $3.2410^{-4} \mathrm{~m} \cdot \mathrm{s}^{-1}$ for stage 3 at $100 \mathrm{~cm}^{3} \cdot \mathrm{h}^{-1}$. The effect of the flow rate on dissolution rate is noticeable in our experiment. The calcite dissolution rate is about 1.38 time faster for stage 2 in comparison to stage 3 (4.09 $10^{-8}$ versus $\left.2.9710^{-8} \mathrm{~mol} \cdot \mathrm{s}^{-1}\right)$. The dependence of the dissolution rate to the flow rate confirms that the transport processes influence the dissolution rate. In more detail, whereas $u$ varies continuously in the course of the experiment due to porosity increase:

- for stage 1 and stage 2 at $300 \mathrm{~cm}^{3} \cdot \mathrm{h}^{-1}$, from $1.2110^{-2}$ to $8.7310^{-3} \mathrm{~m} \cdot \mathrm{s}^{-1}$ (for a porosity variation from $10.8 \%$ to $15.0 \%)$

- for stage 3 at $100 \mathrm{~cm}^{3} \cdot \mathrm{h}^{-1}$, from $2.9110^{-3}$ to $2.5510^{-3} \mathrm{~m} \cdot \mathrm{s}^{-1}$ (for a porosity variation from 15.0 to $17.1 \%$ ), the impact of those weak changes of the fluid velocity is not measurable in the experiment.

\subsection{Permeability-Porosity Relationship}

Figure 9 shows the evolution of permeability and porosity as function of time. Permeability increases rapidly by one order of magnitude in the early minutes of the experiment. In contrast, porosity remains almost unchanged over the same interval of time. In more detail, permeability increases from 40 to $300 \mathrm{mD}$ within stage 1 while porosity variation is estimated at $0.3 \%$. We also observe a permeability jump after
$6 \mathrm{~h} 30 \mathrm{~min}$ of experiment due to a problem in the continuity of pressure measurement. After $9 \mathrm{~h}$ of experiment (during stage 2), the permeability reaches $5000 \mathrm{mD}$ (for a porosity change of about 2.3\%) and the lack of resolution of the pressure sensors does not enable us to measure the permeability precisely.

To compare the possible effect of the flow rate and therefore the effect of transport-reaction on permeability evolution, another experiment was done on a similar core sampled close to that one described in this paper. The results show that the increase in the permeability with time was multiplied by 2 when the flow rate increases from 100 to $300 \mathrm{~cm}^{3} \cdot \mathrm{h}^{-1}$ (Fig. 10). At the same time the change in porosity was multiplied by 1.8 .

The increase of the permeability as function of porosity resulting from the calcite dissolution is plotted in a $\log k$ versus $\log \phi$ diagram (Fig. 11). One can clearly distinguish two distributions with different $\phi-k$ laws. For the early stage of the dissolution, $k$ is proportional to $\phi^{75}$. This extremely high permeability increase is attributed to the concomitant dissolution and release of the micritic mould lodged at pore openings, as observed previously on the tomographic cross sections (see Section 2.2). Micritic elements dissolve more rapidly than sparitic crystals because they present a higher reactive surface (Roques and Ek, 1973). Moreover, the mechanical displacement of the micritic mould at the beginning of the experiment is certainly enhanced by the high hydrodynamic conditions of the experiment; as mentioned by Donaldson et al. (1977), the release of fine particles increases with fluid velocity.

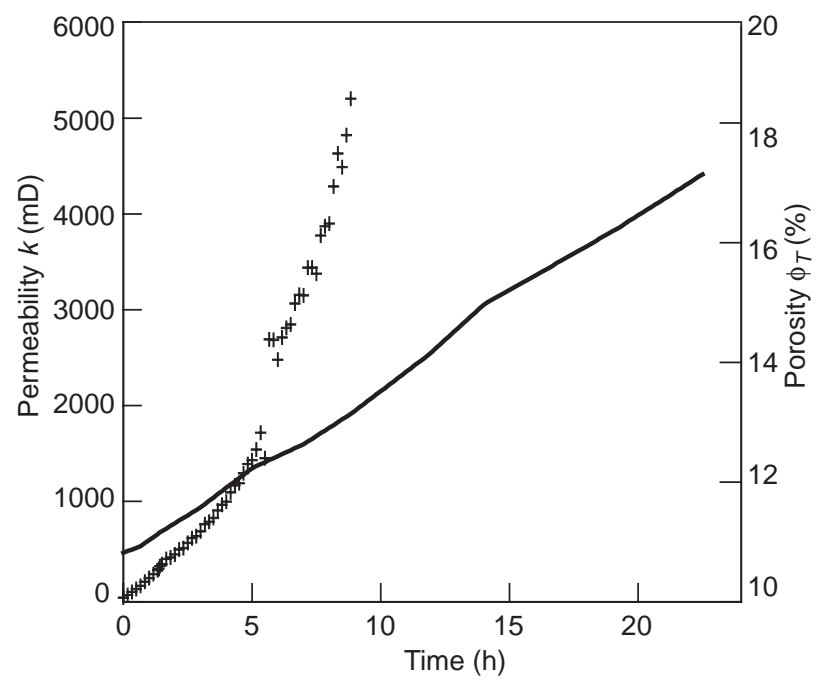

Figure 9

Temporal permeability (cross) and estimated porosity (black line) changes during the reactive percolation experiment. Note that the permeability measurement was stopped after $8 \mathrm{~h} 50 \mathrm{~min}$ of experiment, the corresponding porosity being $13.1 \%$.

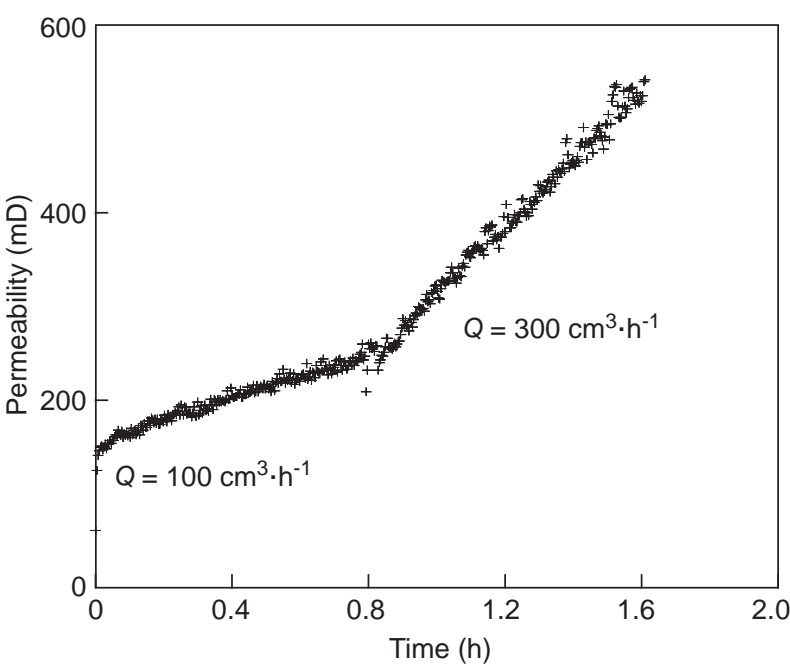

Figure 10

Influence of the flow rate on temporal permeability changes (crosses). Note that the measurements were obtained on a second Lérouville core sample, taken close to the main Lérouville core sample discussed in the preceding figures. 


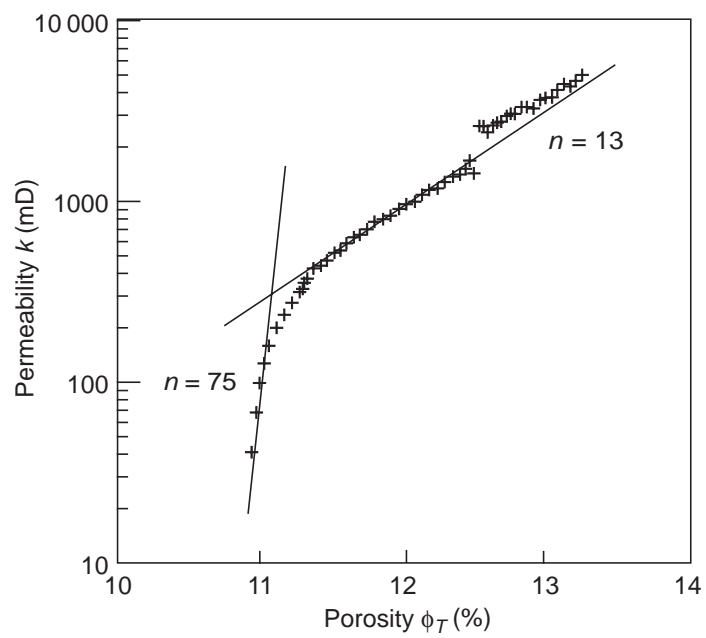

Figure 11

Permeability (crosses) as a function of porosity in a log-log scale.

For the second part of the curve presented in Figure 11, $k$ is proportional to $\phi^{13}$. This high value of $n$ is attributed to the enlargement of connected pores with grain-scale roughness decrease and to connectivity increase. High values of the power law exponent were also reported by other authors when studying chemical alteration or dissolution/precipitation events (e.g. Mc Cune et al., 1979), compared to others processes, for example compaction or sintering.
Hypothesis formulated by Mc Cune et al. (1979) to explain the much larger magnitude of the permeability increase observed in their experiments is that particles may be present in the rock and lodged at the pore openings. In the case where mould is present in these pores, and fills up the path for flow, the permeability can increase dramatically due to pore opening during the removal (both mechanically and chemically) of the mould. In addition, these authors supposed that dissolution takes place within only a small fraction of the total pore space. The process described is very similar to the one observed in the early stage of our experiment: during the removal of the micritic mould, the dissolution globally occurs in only a small fraction of the total pore space (only $27.87 \%$ of the $S V_{t 0}$ surface participates to a significant dissolution).

The permeability value in porous rock being limited by the size of the narrower pore paths, the reaction regime is however also a major controlling factor of the $k$ - $\phi$ relationship. In the case of transport-limited reaction, as the local dissolution rates are proportional to local fluid velocities, the dissolution is greater in narrow channels than in large pore spaces; consequently to the channel widening, the permeability increases more rapidly with time compared to a surface-limited reaction, in which pores grow equally. As the porosity variation is also localized in narrow channels, the permeability increases also more rapidly with porosity compared to a surfacelimited reaction, in which the porosity variation is distribute all around the pores. Figure 12 resumes schematically these two kinds of limited processes; prediction for permeability evolution with time and porosity is also represented. a)

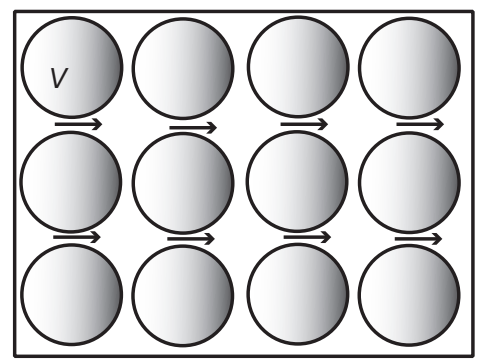

b)

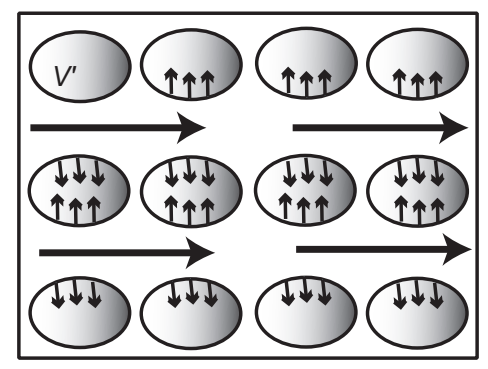

c)

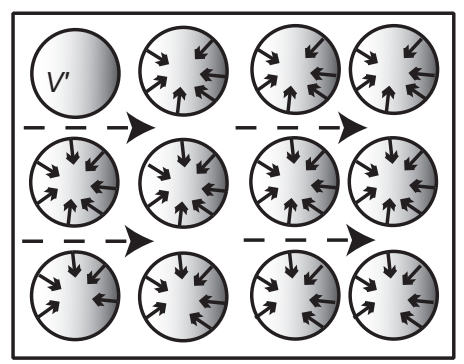

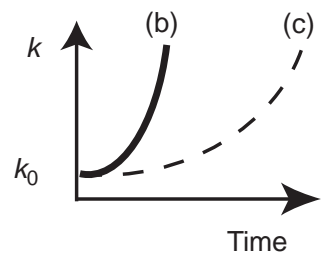

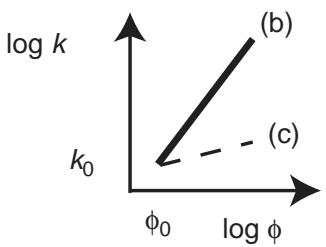

Figure 12

Schematic representation of spherical grain dissolution. The rate of porosity increase is constant with time; the initial and final sphere volumes are respectively $V$ and $V^{\prime}$. Above: a) initial; b) in the case of reaction limited by mass transport: dissolution occurs preferentially in the area of higher flow velocity, i.e. in the sphere sides situated along the narrower pore paths (bold line); c) in the case of surface-limited reaction: dissolution occurs equally on the sphere perimeter (dashed line). Below: permeability prediction for cases b) and c) as function of time and porosity. Note that the value of $n$ exponent will theoretically be higher for case b). 
a)

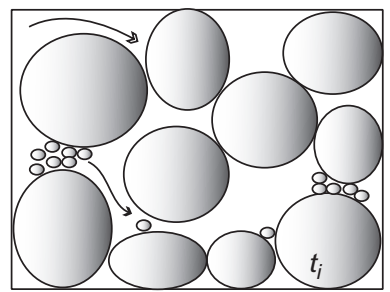

d)

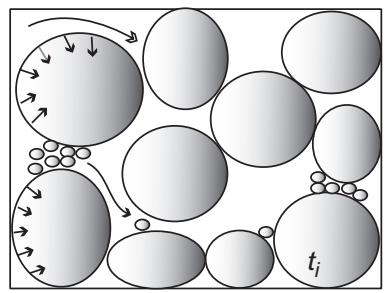

b)

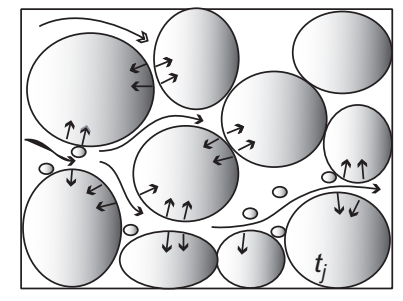

e)

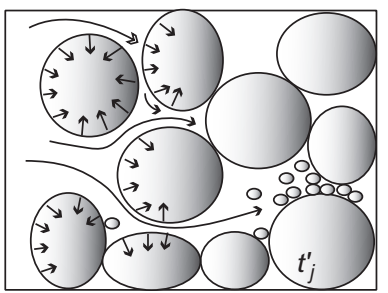

c)

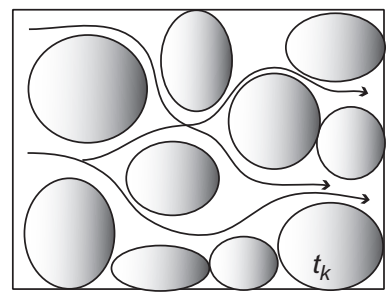

f)

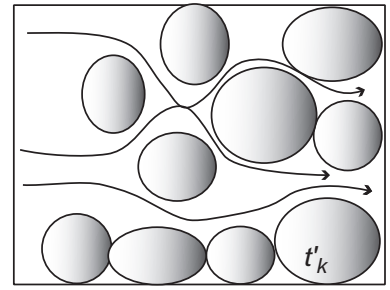

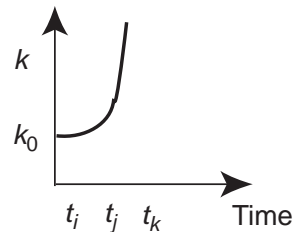

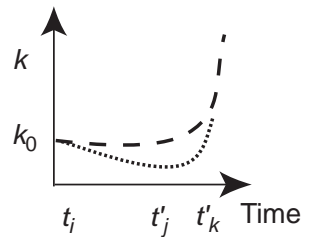

Figure 13

Schematic representation of double grain size assemblage evolution in course of dissolution, as a function of Damköhler number. Above: relative low $D a$, a) $t_{i}$ : preferential dissolution and departure of micritic mould (high reactive surface; b) $t_{j}$ : formation of preferential flow way: permeability increase rapidly; c) $t_{k}$ : increase of pore connectivity. Below: relative high $D a$; d) $t_{i}$ : preferential dissolution of grains and micritic mould at the input of the sample; e) $t^{\prime}{ }_{j}\left(t^{\prime}>t_{j}\right)$ : displacement of mould, and possible pore clogging at the outlet of the sample; results in terms of permeability decrease (dotted line with close spaces) (if not, permeability remains quasi constant (dotted line with large spaces)); f) $t$ ' $k$ $\left(t^{\prime}{ }_{k}>t_{k}\right)$ : pore declogging and rapidly increase of permeability.

It is clear that $k-\phi$ relationship during coupled chemicalflow processes will also depend on the chemical kinetic rate $r$ in regard to the fluid velocity, for a given core length. The evolution of the permeability front is a function of the ratio of the rate at which the chemical reaction occurs to the rate at which the fluid is transported by advection, i.e. the Damköhler number: $D a \propto k L / u$.

Figure 13 summarizes schematically, for an assemblage of grains containing micritic mould, the possible geometry and permeability evolution according to the value of $D a$. For relatively high $D a$, chemical process is important compared to advective flow. The dissolution occurs mainly at the inlet of the sample and chemical equilibrium can be reached rapidly. Micritic mould at the inlet is removed; $k$ may decrease due to pore clogging near the outlet. Permeability increases dramatically when dissolution front reaches the outlet of the sample. For relative low $D a$ (this experiment), the chemical reaction occurs everywhere along the flow axis. Micritic mould is dissolved and rapidly removed; $k$ increases rapidly with time and continues to increase by increasing pore connectivity.

\section{CONCLUSION}

The results from this experimental study throw light on the control by dissolution of microgeometry and flow inside a porous limestone. Processes accompanying flow of $\mathrm{CO}_{2}$ enriched water in a limestone core during $22 \mathrm{~h} 24 \mathrm{~min}$ have been constrained by chemical measurements $\left(\mathrm{pH}, \mathrm{P}_{\mathrm{CO}_{2}}, \mathrm{Ca}\right.$ concentration) at the inlet and outlet of the core and permeability measurement throughout the experiment, together with imaging steps using X-ray microtomography. A new methodology, based on 3D image processing, has been proposed to follow in detail the evolution of the core microstructure and fluid-rock surface during the experiment.

Particle removal observed on 3D imaging of the core geometry involves a large increase in permeability in the early stage of experiment, whereas porosity remains quasi constant over the same time; only a low fraction of the pore space (and so, of the fluid-rock interface) was involved in this process. This phenomenon, assumed during experimental work by Mc Cune et al. (1979), is measured here using a nondestructive imagery technique. The ability to quantify this kind of phenomenon is a main point in reservoir engineering because the particle displacement is commonly expected close to an injection well.

In the following episodes of dissolution, permeability increases by reducing the pore wall roughness and increasing the pore path connectivity, as also observed on the 3D images. Increasing volumetric flow rate also increases the rate of limestone dissolution at low $\mathrm{pH}$, as the calcite rate of dissolution is enhanced by the transport-processes; dissolution rate increases with flow velocity. The permeability increase appears also more marked when the process is transport-limited because the narrow pore paths, where flow velocity is higher, are more rapidly opened. As a general rule, the permeability increase for transport-limited reaction is more rapid compared to surface-limited reaction. 
Presently, X-ray computed microtomography appears to be a useful tool to follow the microgeometry and fluid-rock interface evolution with space and time during dynamic experiments. It allows a better understanding of the coupled reaction-transport process in relation with porosity and hydrodynamic changes. This experimental procedure must now be implemented to investigate reservoir rock samples for conditions more representative of those encountered during $\mathrm{CO}_{2}$ injection (i.e. pressure, $P_{\mathrm{CO}_{2}}$, temperature, hydrodynamics and composition of the different phases). Reliable prediction of permeability changes as a function of time and space is actually a key for setting up effective $\mathrm{CO}_{2}$ injection procedures.

\section{ACKNOWLEDGEMENTS}

We are very thankful to the ESRF-ID19 Team and especially Elodie Boller, Peter Cloetens and José Baruchel for their helpful assistance and for having shared this expertise in microtomography. We also thank at the Institut français $d u$ pétrole (IFP) Etienne Brosse for discussions and suggestions for improvement, Bernard Zinszner for providing the rock sample used in this study and Benoît Vincent for helpful comments about the diagenetic history of the rock. This research was carried out as a part of PICOR project.

\section{REFERENCES}

Aharonov, E., Rothman, D.H. and Thompson, A.H. (1997) Transport properties and diagenesis in sedimentary rocks: the role of micro-scale geometry. Geology, 25, 6, 547-550.

Auzerais, F.M., Dunsmuir, J., Ferréol, B.B., Martys, N., Olson, J., Ramakrishnan, S., Rothman, D.H. and Schwartz, L.M. (1996) Transport in sandstone: A study based in three-dimensional microtomography. Geophysical Research Letters, 23, 7, 705-708.

Bernard, D., Gendron, D., Bordere, S. and Heintz, J.M. (2002) First direct $3 \mathrm{D}$ visualisation of microstructural changes during sintering. ESRF Highlights 2001, 102-103.

Bernard, D., Gendron, D., Heintz, J.M., Bordere, S. and Étourneau, J. (2004) First direct 3D visualisation of microstructural evolutions during sintering through X-ray computed microtomography. Submitted to Acta Materialia.

Bernabé, Y. and Revil, A. (1995) Pore-scale heterogeneity, energy dissipation and the transport properties of rocks. Geophysical Research Letters, 22, 12, 1529-1532.

Bernabé, Y, Mok, U. and Evans, B. (2003) Permeability-porosity relationships in rocks subjected to various evolution processes. Pure and Applied Geophysics, 160, 937-960.

Bourbié, T. and Zinszner, B. (1985) Hydraulic and acoustic properties as function of porosity in Fontainebleau sandstone. Journal of Geophysical Research, 90, 11524-11532.

Brosse, E., Magnier, C. and Vincent, B. (2005) Modelling fluidrock interaction induced by the percolation of $\mathrm{CO}_{2}$-enriched solutions in core samples: 1 . The role of reactive surface area. Oil \& Gas Science and Technology, this issue.

Carman, P.C. (1937) Fluid flow through granular beds. Transactions for Institute of Chemical Engineer, 15, 150-166.

Chou, L., Garrels, R.M. and Wollast, R. (1989) Comparative study of the kinetics and mechanisms of dissolution of carbonate minerals. Chemical Geology, 78, 269-282.
Coker, D.A., Tortaquo, S. and Dunsmuir, J.H. (1996) Morphology and physical properties of Fontainebleau sandstone via a tomographic analysis. Journal of Geophysical Research, 101, B8, 17497-17506.

Cole, M.E., Hazlett, R.D., Muegge, E.L., Jones, K.W., Andrews, B., Dowd, B., Siddons, P., Peskin, A., Spanne, P. and Soll, W.E. (1996) Developments in synchrotron X-Ray microtomography with applications to flow in porous media. SPE-36531. In: Annual Technical Conference and Exhibition Proceedings, V. Omega, Formation Evaluation and Reservoir Geology, SPE, 413424.

Coudrain-Ribstein, A., Gouze, P. and de Marsily, G. (1998) Temperature - carbon dioxide partial pressure trends in confined aquifers. Chemical Geology, 145, 73-89.

David, C., Wong, T.F., Zhu, W. and Zhang, J. (1994) Laboratory measurement of compaction-induced permeability change in porous rock: implications for the generation and maintenance of pore pressure excess in the crust. Pure and Applied Geophysics, 143, 425-456.

Delerue, J.F., Perrier, E., Yu, Z.Y. and Velde, B. (1999) New algorithms in 3D image analysis and their application to the measurement of a spatialized pore size distribution in soils. Physics and Chemistry of the Earth (A), 24, 7, 639-644.

Donaldson, E.R., Baker, B.A. and Carroll, H.B. (1977) Particle transport in sandstones. SPE-6905. In: $52^{\text {nd }}$ Annual Fall Technical Conference and Exhibition of the SPE of AIME, Denver CO, USA, Oct. 9-12.

Gouze, P., Noiriel, C., Bruderer, C., Loggia, D. and Leprovost, R. (2003) X-ray tomography characterization of fracture surface during dissolution. Geophysical Research Letters, 30, 5, 71-1-71-4.

Hammersley, A.P. (2001)

http://www.esrf.fr/computing/scientific/HST/HST_REF/hst.html.

Lackner, K.S. (2003) A guide to $\mathrm{CO}_{2}$ sequestration. Sciences, 300, 1677-1678.

Landis, E.N, Nagy, E.N and Keane, D.T. (2003) Microstructure and fracture in three-dimensions. Engineering Fracture Mechanics, 70, 911-925.

Lasaga, A.C. (1981) Transition state theory. In: Kinetics of Geochemical Processes, A.C. Lasaga and R.J. Kirkpatrick, Eds., Reviews in Mineralogy, 8, 135-169.

Lindquist, W.B., Lee, S.M., Coker, D.A., Jones, K.W. and Spanne, P. (1996) Medial axis analysis of void structure in threedimensional tomographic images of porous media. Journal of Geophysical Research, 101, 8297-8310.

Lindquist, W.B. and Venkatarangen, A. (2000) Pore and throat size distributions measured from synchrotron X-ray tomographic images of Fontainebleau sandstones. Journal of Geophysical Research, 105, B9, 21509-21527.

Mc Cune, C.C., Fogler, H.S. and Kline, W.E. (1979) An experimental technique for obtaining permeability-porosity relationships in acidized porous media. Industrial Engineering Chemical Fundamentals, 18, 188-191.

Mok, U., Bernabé, Y. and Evans, B. (2002) Permeability, porosity and pore geometry of chemically altered porous silica glass. Journal of Geophysical Research, 107, B1, 4-1-4-10.

Nakashima, Y. and Watanabe, Y. (2002) Estimate of transport properties of porous media by microfocus X-ray computed tomography and random walk simulation. Water Resources Research, 38, 12, X1-X12.

Pape, H., Clauser, C. and Iffland, J. (1999) Permeability prediction based on fractal pore-space geometry. Geophysics, 64 , $5,1447-1460$.

Plummer, L.N. and Busemberg, E. (1982) The solubility of calcite, aragonite and vaterite in $\mathrm{CO}_{2}-\mathrm{H}_{2} \mathrm{O}$ solutions between 0 and $90^{\circ} \mathrm{C}$, and a evaluation of the aqueous model for the system 
$\mathrm{CaCO}_{3}-\mathrm{CO}_{2}-\mathrm{H}_{2} \mathrm{O}$. Geochemica and Cosmochemica Acta, 46, 1011-1040.

Plummer, L.N., Wigley, T.M.L. and Parkhurst, D.L. (1978) The kinetics of calcite dissolution in $\mathrm{CO}_{2}$-water systems at $5^{\circ}$ to $60^{\circ} \mathrm{C}$ and 0.0 to $1.0 \mathrm{~atm} \mathrm{CO}_{2}$. American Journal of Science, 278, 179216.

Proussevitch, A.A. and Sahagian, D.L. (2001) Recognition and separation of discrete objects within complex 3D voxelized structures. Computers and Geosciences, 27, 4, 441-454.

Revil, A. and Cathles, L.M. (1999) Permeability of shaly sands. Water Resources Research, 35, 3, 651-662.

Richard, P., Philippe, P., Barbe, F., Bourles, S., Thibault, X. and Bideau, D. (2003) Analysis by $\mathrm{x}$-ray microtomography of a granular packing undergoing compaction. Physical Review E, 68, 020301.
Rickard, D. and Sjöberg, E.L. (1983) Mixed kinetic control of calcite dissolution rates. American Journal of Science, 283, 815830 .

Roques, H. and Ek, C. (1973) Etude expérimentale de la dissolution des calcaires par une eau chargée de $\mathrm{CO}_{2}$. Annales spéléologie, 28, 4, 549-563.

Spanne, P., Thovert, J.F., Jacquin, C.J., Lindquist, W.B., Jones, K.W. and Adler, P.M. (1994) Synchrotron computed microtomography of porous media: topology and transports. Physical Review Letters, 73, 14, 2001-2004.

Walsh, J.B. and Brace, W.F. (1984) The effect of pressure on porosity and the transport properties of rock. Journal of Geophysical Research, 89, 11, 9425-9431.

Final manuscript received in November 2004 or distributed for profit or commercial advantage and that copies bear this notice and the full citation on the first page. Copyrights for components of this work owned by others than IFP must be honored. Abstracting with credit is permitted. To copy otherwise, to republish, to post on servers, or to redistribute to lists, requires prior specific permission and/or a fee: Request permission from Documentation, Institut français du pétrole, fax. +33147527078 , or revueogst@ifp.fr. 